\title{
OPTIMIZATION OF ROLL BONDING BY HOT ROLLING IN EXPERIMENTAL AND INDUSTRIAL USE
}

In this study the major topic were the bonding properties of the layer-clad aluminum sheets. The bonding was performed between AlMn1Si0.8 and AlSi10 alloys using hot rolling (a VON ROLL experimental duo mill). The experimental temperatures were 460,480 and $500^{\circ} \mathrm{C}$. The goodness of bonding was tested by tensile test and T-peel test. T-peel test provided a good description about the quality of bonding. Structure analysis was also performed by light microscopy to detect typical bonding faults. The aim of this investigation is modelling the bonding conformation in experimental conditions. Further aim of this investigation is to produce some typical bonding faults and find the cause of formation. The influence of the rolling temperature and surface roughness on the bonding was also analyzed. Rolling schedule and the role of first pass on the development of perfect bonding were experimentally determined.

Keywords: sandwich sheet rolling, aluminum-plating technology, welding by rolling, pressure welding, bonding faults

\section{Introduction}

Aluminum cladding technology is used worldwide, not only in the automotive industry but also in household items. The core of the technology is that a layer with a certain property is cladded with another layer with different properties. The understanding of the bond development is highly important, because these sheets have high added value. In previous studies it was determined that cladding technology by rolling can weld sheets that normally cannot be welded by means of conventional technologies. Roll welding is a type of pressure welding, where bond develops through plastic deformation. [1-6] The goodness of bond development depends on the deformations. Bonding does not occur until the deformation reaches a threshold value. [1-3,6] Once deformation reaches a threshold value, the goodness of bonding dynamically increases until it attains the basic material tensile strength. [1-2,6-7] This threshold value varies from material to material. [1-2,4] Bond development is influenced by surface roughness and surface preparations. [1-2,4-5,8] In a previous study a numerical value of bonding goodness was investigated. [9] The aim of this study is to illustrate several bonding faults and to analyze the influence of surface roughness and surface preparations at different temperatures and deformation rates. Further on, the influence of the temperature and surface roughness on bond development was also investigated. T-peel test can provide numerical values about bonding goodness. This fact was also mentioned in a previous study [9].

\section{Experimental procedure}

In the test three layer-plated sandwich sheets were produced. The core alloy was AlMn1Si0,8 while the liner was AlSi10. During the assembly of the designed sandwich sheets it was endeavored to keep symmetry. The tests were carried out on a Von Roll experimental roll mill installed at the Institute of Physical Metallurgy, Metalforming and Nanotechnology at the University of Miskolc. The roll mill can be seen during experiment in Figure 1. Table 1 lists the dimensions of the assembled three-layer package.

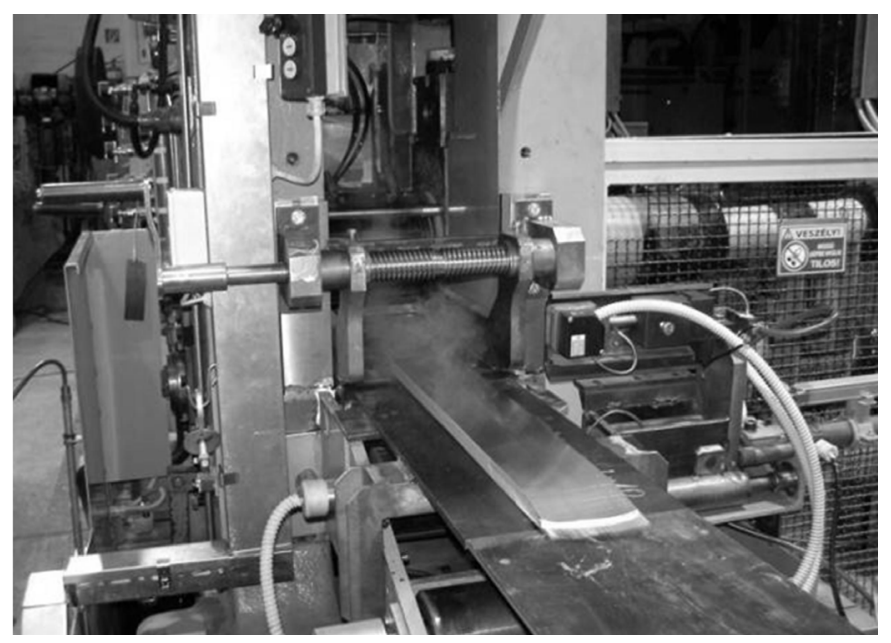

Fig. 1. Clad rolling

INSTITUTE OF PHYSICAL METALLURGY, METAL FORMING AND NANOTECHNOLOGY, UNIVERSITY OF MISKOLC, H-3515 MISKOLC-EGYETEMVÁROS, B1/107, HUNGARY

\# Corresponding author: szabogabor@uni-miskolc.hu 
TABLE 1 also analyzed. Until the 5th pass the sandwich structures were

Geometrical parameters of sheets

\begin{tabular}{|c|c|c|c|}
\hline \hline Type of layers & $\begin{array}{c}\text { Length, } \\
\text { mm }\end{array}$ & $\begin{array}{c}\text { Width, } \\
\text { mm }\end{array}$ & $\begin{array}{c}\text { Thick- } \\
\text { ness, } \mathbf{~ m m}\end{array}$ \\
\hline Core & 200 & 50 & 25,0 \\
\hline Liners & 195 & 50 & 2,5 \\
\hline
\end{tabular}

Table 2 presents the rolling schedule and parameters. In the first 7 passes of rolling small deformation occurred, at a rolling speed of $5 \mathrm{~m} / \mathrm{sec}$. These parameters were chosen to have an optimum bond development performance. During further rolling, rolling speed and deformation per pass were increased. In a previous study the cause of bond development was tested. If the bond development does not occur in the first few passes between the layers, nor will it during further rolling.

TABLE 2

Rolling schedule

\begin{tabular}{|c|c|c|c|c|c|c|}
\hline \hline Pass & $\begin{array}{c}\text { Inbound } \\
\text { sheet height } \\
\text { (meas.), mm }\end{array}$ & $\begin{array}{c}\text { Reduc- } \\
\text { tion, } \\
\text { mm }\end{array}$ & $\begin{array}{c}\text { Rolling } \\
\text { speed, } \\
\text { m/min }\end{array}$ & $\begin{array}{c}\text { Sheet } \\
\text { temp. } \\
\text { after } \\
\text { pass, }{ }^{\circ} \mathbf{C}\end{array}$ & $\begin{array}{c}\text { Outbound } \\
\text { heet height } \\
\text { (calc.), mm }\end{array}$ & $\begin{array}{c}\text { Reheat- } \\
\text { ing } \\
\text { time, } \\
\text { min }\end{array}$ \\
\hline 1 & 30.0 & 0.4 & 5.2 & 480 & 29.6 & 15 \\
\hline 2 & 29.7 & 0.4 & 5.2 & 475 & 29.3 & 15 \\
\hline 3 & 29.3 & 0.4 & 5.2 & 472 & 28.9 & 15 \\
\hline 4 & 28.9 & 0.4 & 5.2 & 470 & 28.5 & 10 \\
\hline 5 & 28.5 & 0.4 & 5.2 & 465 & 28.1 & 8 \\
\hline 6 & 28.2 & 0.5 & 5.2 & - & 27.7 & - \\
\hline 7 & 27.8 & 0.5 & 7.5 & 438 & 27.3 & 8 \\
\hline 8 & 27.4 & 0.6 & 7.5 & - & 26.8 & - \\
\hline 9 & 26.9 & 0.8 & 7.5 & 434 & 26.1 & 7 \\
\hline 10 & 26.2 & 1 & 11.2 & - & 25.2 & - \\
\hline 11 & 25.3 & 1 & 11.2 & 416 & 24.3 & 6 \\
\hline 12 & 24.4 & 1 & 11.2 & - & 23.4 & - \\
\hline 13 & 23.5 & 1 & 11.2 & 398 & 22.0 & 6 \\
\hline 14 & 22.1 & 1.5 & 11.2 & - & 20.6 & - \\
\hline 15 & 20.7 & 1.5 & 11.2 & 388 & 19.3 & 6 \\
\hline 16 & 19.3 & 1.5 & 11.2 & - & 17.8 & - \\
\hline 17 & 17.9 & 1.5 & 11.2 & 354 & 16.4 & 6 \\
\hline 18 & 16.5 & 1.5 & 11.2 & - & 15 & - \\
\hline 19 & 15 & 1.5 & 11.2 & 331 & 13.5 & - \\
\hline 20 & 13.6 & 1.5 & 11.2 & - & 12.1 & - \\
\hline 21 & 12.2 & 1.5 & 11.2 & - & 10.7 & - \\
\hline 22 & 10.7 & 1.5 & 11.2 & - & 9.2 & - \\
\hline 23 & 9.2 & 1.5 & 11.2 & - & 8.2 & - \\
\hline 24 & 8.2 & 1 & 11.2 & - & 7.2 & - \\
\hline 25 & 7.2 & 1 & 11.2 & - & 6.2 & - \\
\hline
\end{tabular}

Fig. 1 presents the VON ROLL experimental duo mill during plated sheet rolling. The investigation of plated sheet rolling was performed at three different temperatures, namely 460, 480 and $500^{\circ} \mathrm{C}$. The furnace temperature was set $20^{\circ} \mathrm{C}$ higher than the experimental temperatures. Surface roughness of the entire sandwich structures was changed. In addition, the influence of the grease applied on some layers during production was reheated after every pass. After this pass, reheating was carried out after every 2 passes. In another experiment the process of bond development was investigated. Identical sandwich structures were plated. Every sandwich structure underwent different passes. Longitudinal deformations of some layers were investigated after the passes. The rolling speed was $5 \mathrm{~m} / \mathrm{min}$ and the temperature was $500^{\circ} \mathrm{C}$.

\section{Results and discussion}

During the experiments it was seen in accordance with the previous statements that deformation needs to reach a critical value so that a detectable bond can develop between the layers [9]. Based on the peel test performed, the diagrams presented in Figure 2 were obtained. The range bond developed between specific layers can be well distinguished. To compare results from the T-peel test with the tensile strengths of each base material, the measured force must be converted into stress. Assuming that the front is situated along a line during peel test, the surface can be well approximated with the product of part width and thickness of peeled off liner. The ratio of the peel-off stress calculated and the tensile strength of base material shows how many percentage of contacting surfaces is involved in bond development. Figure 3 illustrates the ratio of bonds developed between specific layers vs. temperature. The experiment was performed on three different temperatures $\left(460,480,500^{\circ} \mathrm{C}\right)$, as shown in previous study [10]. In addition, it was experienced that if no bond develops in some of the first passes then - no matter how high deformation is set - (in line with technological constraints) no bond is developed between layers. Therefore, it is very important to follow the applied roll technology strictly in the first passes. Also, it was determined that deformations applied in the passes after some of the first passes are too large, it affects the developed bond negatively.

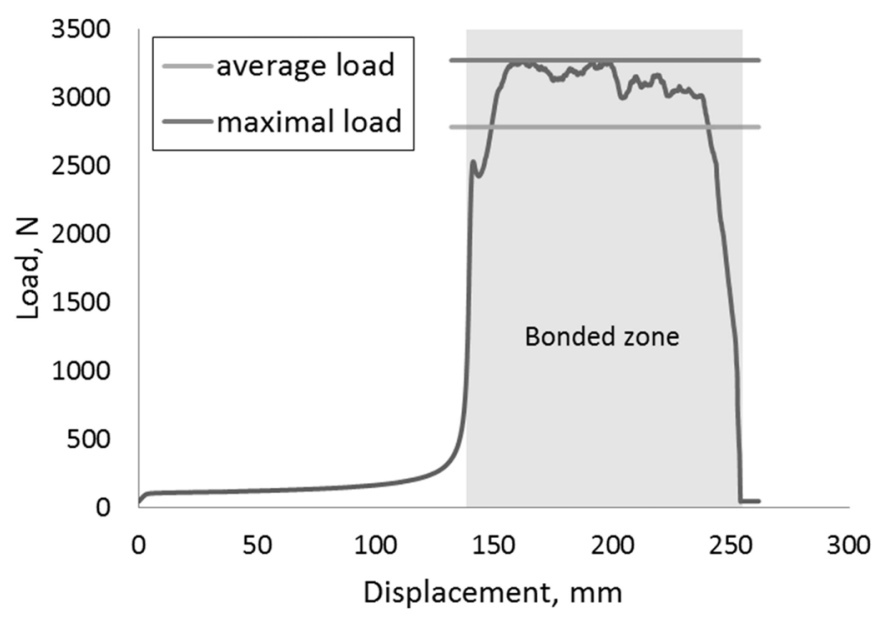

Fig. 2. Evolution of peel-off force

According to our experience, about 2\% deformation can ensure a bond development with the best specific surface. 


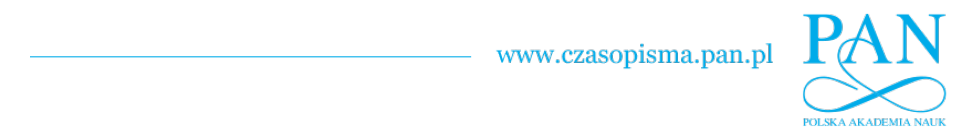

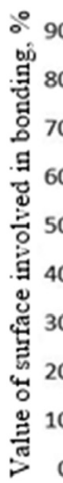

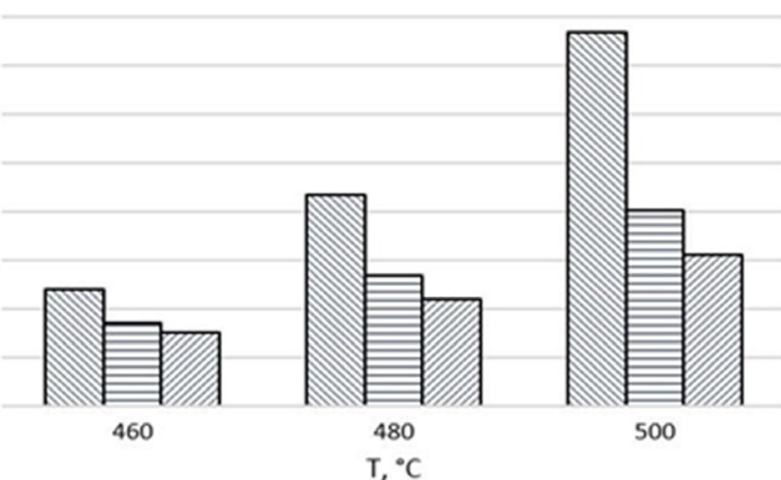

\$roughened, degreased Edegreased

$\square$ untreated

Fig. 3. Value of bond developed between surfaces

For deformations lower or higher than this, the developed bond strength deteriorates and after few of the next passes layers peel off. This is due to specific layers undergoing longitudinal deformation in the roll gap. Figure 4 shows the longitudinal deformation of specific layers vs. reduction applied in each 6 passes.

It was also determined that bond development can be considered optimal if the longitudinal deformation of contacting but not yet bonded surfaces differ considerably. After the development of partial bond it is practical to keep longitudinal deformation of specific layers at the same rate, or else the elon-

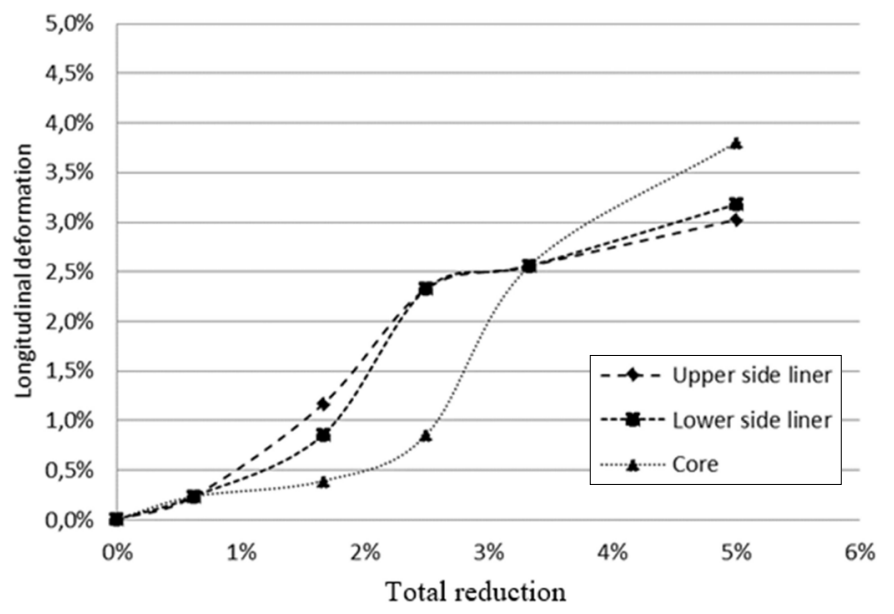

Fig. 4. Longitudinal deformation of specific layers vs. reduction

gation of the already partially liner clogs and tears off the liner from the core. Such a wave can be seen in Figure 5 .

The other aim of the study is to produce and examine some typical bond faults, which is encountered in industry unfortunately frequently. Such a fault is for instance a liner with bubbles or blisters, which means that on surface of thin-rolled plated sheets small air inclusions appear. This is due to the initial technology. If the surface preparation is not appropriate or surface roughening is overly deep and air bubbles appear between contacting surface, these are not able to exit during further roll-
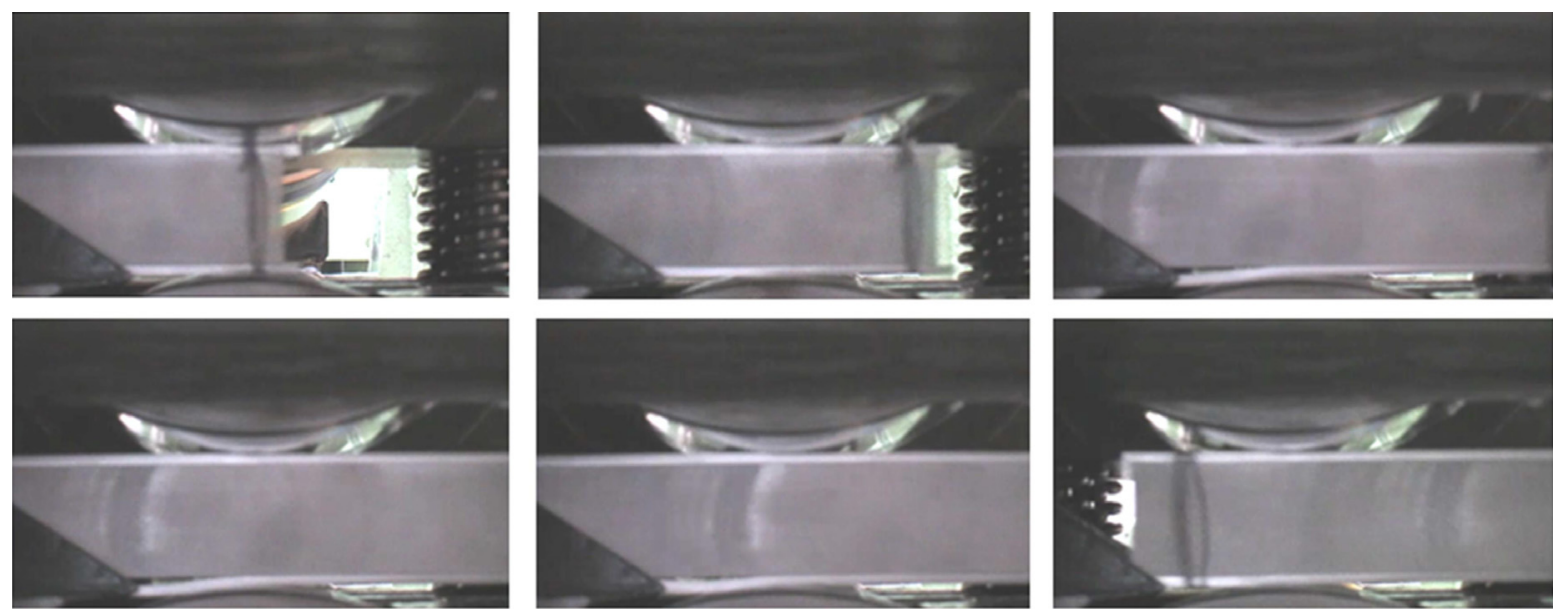

Fig. 5. Upper side liner tearing off due to clogging deformation

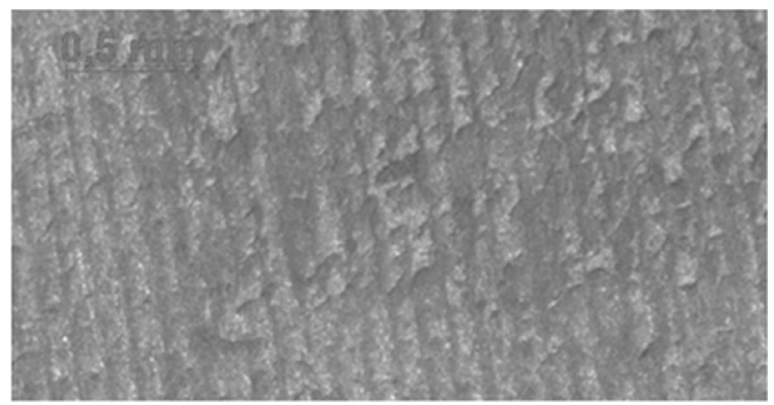

a. $460{ }^{\circ} \mathrm{C}$

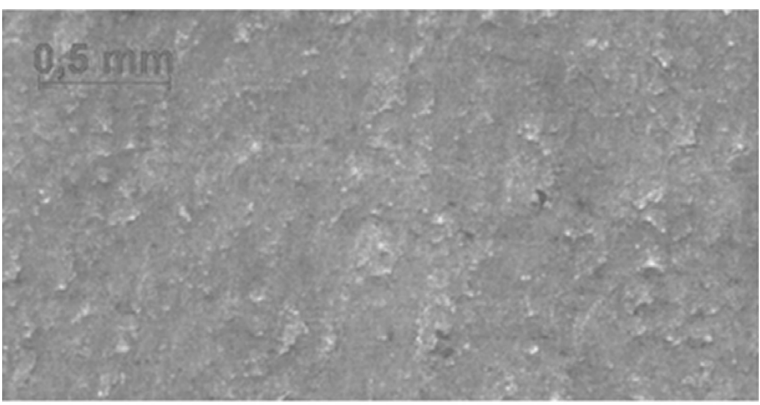

b. $500^{\circ} \mathrm{C}$

Fig. 6. Surface roughness lines of sheets plated at various temperatures after peel test 
ing. In case of too low plating temperature bond only develops where roughness peak meets roughness peak. Figure 6 reveals that in case of plated sheets plated at 460 and $500^{\circ} \mathrm{C}$ after peel test, to what extent surface roughness lines appear or disappear.

It can be stated that in case of imperfect preheating or any technological anomaly, the surface of parts undercool, thereby reducing the size of surface developed in the bond significantly. If contact is not perfect, the enclosed air appear as bubble or blister in the end product.

The traces of such air inclusion are presented in Figure 7 by means of optical microscopy and SEM images.

\section{Conclusion}

Our experiments reveal that the Von Roll experimental roll mill is suitable for experimental modelling of industrial technology. The obtained results confirm that the state of initial surfaces has a serious effect on the developed bond but rolling

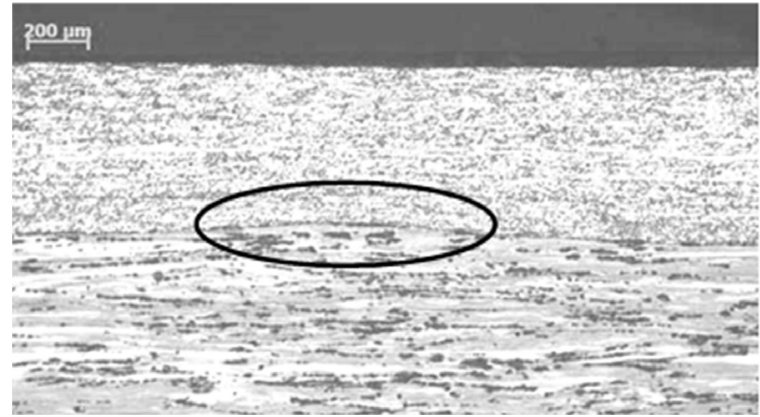

Fig. 7. Traces of air inclusion and improperly welded surface

work of the New Széchenyi Plan. The realization of this project is supported by the European Union, and co-financed by the European Social Fund.

\section{REFERENCES}

[1] N. Bay, Cold welding Part I Characteristic bonding mechanisms bond strength, Met. Const. 369 (1986).

[2] M. Eizadjou, H. Danesh Manesh, K. Janghorban, Mechanism of warm and cold roll bonding of aluminum alloy strips, Mat. and Des. 4156 (2009).

[3] W. Zhang, N. Bay, Cold welding-theoretical modeling of weld formation, J. Weld. 417 (1997).

[4] P.K. Wright, D.A. Snow, C.K. Tay, Interfacial conditions and bond strength in cold pressure welding by rolling, Met. Technol. 24 (1978). temperature has an even higher effect. In contrast to previous literature statements however, the value of bond strength for this material-pair does not rise further reaching a critical deformation and due to the different horizontal elongation the bond tears off when exiting the rolling gap.

A large part of typical surface faults is formed already in the initial steps, but only possible to be revealed in case of further rolled sheets. However, this does not allow a subsequent intervention, therefore it is crucial to follow strictly the initial rolling technology.

\section{Acknowledgements}

The authors would like to express their gratitude to Tamás Mikó for the T-Peel examinations and to Valéria Mertinger for the consultant support.

The research work presented in this paper based on the results achieved within the TÁMOP-4.2.1.B-10/2/KONV-2010-0001 project and carried out as part of the TÁMOP-4.2.2.A-11/1/KONV-2012-0019 project in the frame-

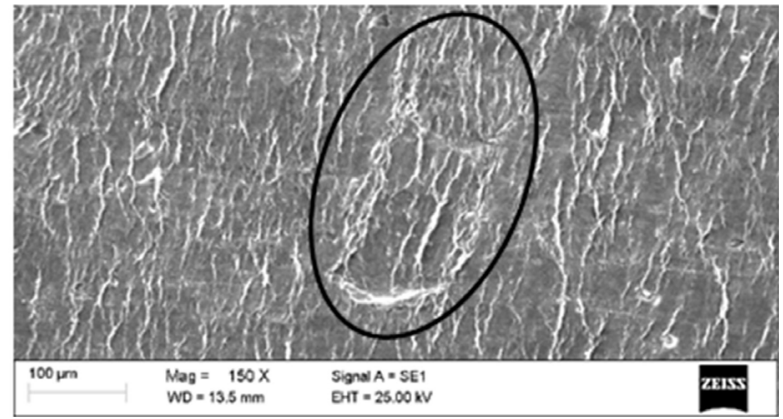

5] H.Y. Wu, S. Lee, J.Y. Wang, Solid state bonding of iron-base alloy, steel-brass and aluminum alloy, J. Mat. Proc. Techn. 173 (1998).

[6] H. Danesh Manesh, A. Karimi Taheri, Study of mechanisms of cold roll welding of aluminum alloy to steel strip, J. Mater. Sci. Technol. 1064 (2004).

[7] H. Danesh Manesh, A. Karimi Taheri, An investigation of deformation behavior and bonding strength of bimetal strip during rolling, Mech. Mater. 531 (2005).

[8] W. Zhang, N. Bay, Cold welding-experimental investigation of the surface preparation methods, J. Weld. 326 (1997).

[9] G. Szabó, V. Mertinger, Technological investigation of plated aluminium sheets, Mater. Sci. F. 729, 482 (2013).

[10] G. Szabó, V. Mertinger, Investigation of typical bonding faults of plated Al sheets developed during rolling, Mater. Sci. F. 812, 387 (2015). 